\title{
Weathering-induced deformation of crushed weak rocks and its countermeasure
}

\author{
Andius D. Putra ${ }^{1}$, Masaya Takahashi ${ }^{2}$ and Mamoru Kikumoto ${ }^{1, *}$ \\ ${ }^{1}$ Department of Civil Engineering, Yokohama National University, Yokohama, Japan \\ ${ }^{2}$ Oriental Consultant Co. Ltd
}

\begin{abstract}
Geotechnical issues such as differential settlements have been reported usually in embankments made of materials derived from weak rocks such as mudstones, siltstones, and shales. The primary cause of the issue is a gradual weakening due to weathering. Crushed weak rocks tend to turn into smaller particles under repeated wetting and drying processes. This phenomenon is a mechanical-hydraulic process known as "slaking". The present paper discusses the deformation of crushed weak rocks due to slaking and its countermeasure. We performed a series of one-dimensional slaking tests on several weak rocks. We first performed one-dimensional compression tests on dried samples, and applied wetting and drying cycles to the samples while keeping the compression stress constant. The test results revealed that particle size distribution of the samples was broadened due to cyclic wetting and drying processes and that significant compression was exhibited. Moreover, we explored possible countermeasures for reducing the slakinginduced deformation and revealed that compacting the soil to a denser state is the most effective way in reducing the slaking-induced deformation of the crushed mudstone.
\end{abstract}

\section{Introduction}

Granulated weak rocks are usually derived by cutting slopes and excavating tunnels, and they are widely utilized for the earth construction such as embankments. They, however, tend to be weathered relatively quickly once they are immersed in the water. This phenomenon is a kind of weathering processes known as slaking. Slaking is a kind of hydro-mechanical process (Figure 1), which may cause the reduction of stiffness and peak strength, resulting in differential settlement or reduction of seismic resistance.

Several researchers have discussed the mechanism of the slaking of geomaterials derived from weak rocks. Mitchell [1] pointed out three primary mechanisms of slaking: (a) dispersion of soil particles consisting of rocks; (b) swelling of rocks due to stress release and water absorption; and (c) tensile stress resulting from compression of entrapped air due to water absorption. Slaking resistance of granulated shales, mudstones, and siltstones have been investigated through the slakedurability tests [2-4]. Unconfined compression tests on granulated weak rocks that experienced different slaking cycles revealed the significant reduction of the peak strength due to wetting and drying cycles [5-7]. Slaking evolves the particle size distribution $[8,9]$, and this evolution varies the stiffness and strength resulting significant deformation of the soil [9].

This paper attempts to address the slaking-induced deformation based on the one-dimensional compression slaking tests [9] and to propose a rational way to overcome the issues of the granulated weak rocks in the earth construction projects.
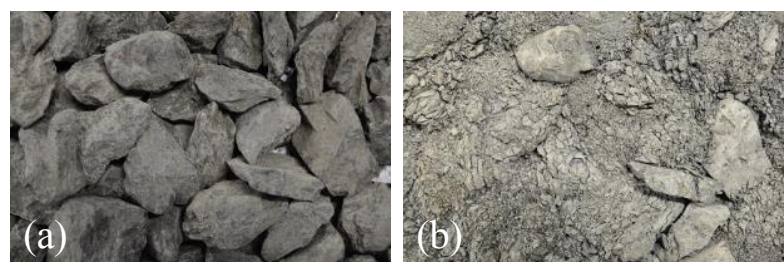

Fig. 1. Slaking of crushed mudstone (a) initial condition and (b) after slaking (an example of the accelerated slaking tests).

\section{Materials and methods}

\subsection{Geomaterials}

In this paper, Kakegawa, Nou and Hattian Bala mudstones are used for the one-dimensional compression slaking tests. They were originated from several embankments which caused deformation issues due to slaking phenomena. Kakegawa mudstone was derived from the embankment on Tomei expressway in Japan. Hattian Bala mudstone was obtained from a natural dam which is generated by Kashmir earthquake 2005 that locates at $3.5 \mathrm{~km}$ of Karli River in Pakistan. Toyoura sand is also used as a comparative material to reveal the difference of the behavior from those of mudstones.

In addition, to investigate the rational countermeasures to the issues related with the weak rocks in embankments, loading histories (loading/unloading) were applied before the wetting and drying cycles. The test was carried out on

\footnotetext{
* Corresponding author: kikumoto@ynu.ac.jp
} 
Nou mudstone since the deformation issues in the field has occurred due to slaking. The particle size distribution of mudstone specimens at the initial state of the onedimensional compression slaking test was a unit grading having a diameter of 0.85-2.00 $\mathrm{mm}$ (passed by sieve no. 10 and restrained by sieve no. 20 ASTM [13]). General properties of the material are summarized in Table 1.

According to previous studies, several mechanisms of the slaking of weak rocks were attributed to the compression of air entrapped in the intra-granular pores of the particles [3]. Moreover, the size and the roughness of the pore boundaries have dominant effects on the resistance of particles against slaking. Therefore, it is necessary to explore the surface characteristics of the granulated weak rocks through SEM analysis using the same particle size distribution for one-dimensional compression slaking test.

Table 1. General properties of geomaterials

\begin{tabular}{|l|c|c|c|c|}
\hline Properties & A & B & C & D \\
\hline Particle density $\left(\mathrm{gr} / \mathrm{cm}^{3}\right)$ & 2.65 & 2.75 & 2.69 & 2.65 \\
\hline Max. Void ratio $\left(\mathrm{e}_{\max }\right)$ & 1.83 & 1.09 & 1.97 & 0.98 \\
\hline Min. Void ratio $\left(\mathrm{e}_{\min }\right)$ & 1.29 & 0.79 & 1.40 & 0.61 \\
\hline Geological period & \multicolumn{5}{|c|}{ Neogene } & -- \\
\hline
\end{tabular}

Note:

$\begin{array}{llll}\text { A } & \text { : Kakegawa mudstone } & \text { C } & \text { : Nou mudstone } \\ \text { B } & \text { : Hattian Bala mudstone } & \text { D } & \text { : Toyoura sand }\end{array}$
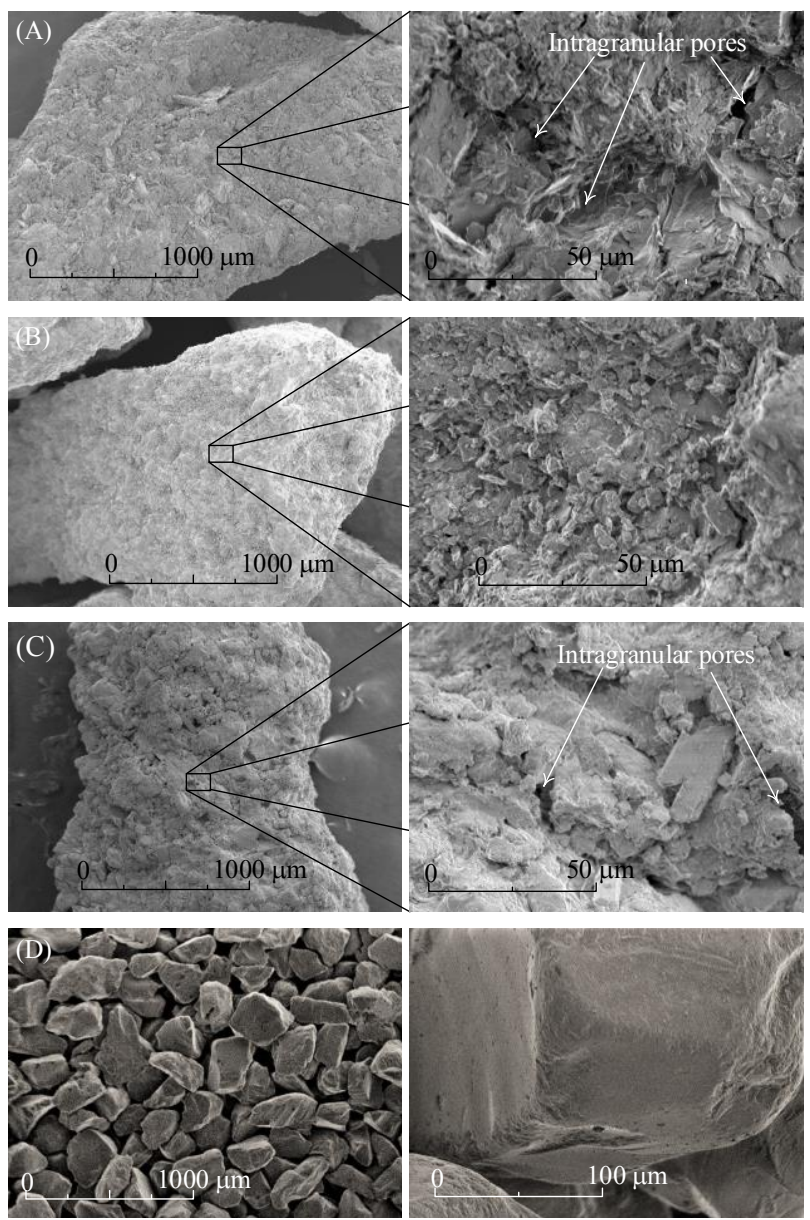

Fig. 2. SEM images of the geomaterials: (a) Kakegawa mudstone; (b) Hattian Bala mudstone; (c) Nou mudstone and (d) Toyoura sand.
The low-magnification images of each specimen on the left-hand side in Figure 2 clearly demonstrate that each particle is in fact an aggregate of randomly shaped, claysized particles that produce a rough surface texture. This surface texture can be proper seen in the higher magnification images on the right-hand side in Figure 2. It is noted that there is a particularly pronounced accumulation of tiny particles, with apparent intragranular pores appearing to form within each bulk particle of Kakegawa and Nou mudstone. In comparison, the surface texture of the Hattian Bala mudstone seems to be smoother but is still rougher than the Toyoura sand particle.

\subsection{One dimensional compression slaking tests}

In order to evaluate the slaking induced deformation on mudstone, we would like to introduce a onedimensional compression test that incorporates wetting and drying cycles. The schematic setup of testing apparatus is shown in Figure 3, and consisted of: a measuring system (left), loading system (center), and wetting and drying paths (right). The specimen container was a rigid steel cylinder measuring $60 \mathrm{~mm}$ in diameter and $40 \mathrm{~mm}$ high, with porous stones installed on the top and bottom loading plates, respectively. The vertical load was controlled by a pneumatic cylinder and measured by a load cell, with the vertical displacement then being measured by a displacement gauge. The porous stone installed on the bottom plate was connected to the inlet of the wetting and drying path. The wetting path was connected to a supply of carbon dioxide and de-aerated, distilled water. The tank used for the distilled water was connected to a vacuum pump for de-aeration, but was opened to the atmosphere when sending water to the specimen. The drying path consisted of a drainage path that was opened to atmospheric pressure, and an input path connected to a tank filled with compressed air dried by silica gel.

For testing, dried specimens were first installed in the steel cylinder, after which the load cell and contact-type displacement gauge were installed and initialised. The initial height of the specimen was measured to determine the initial void ratio, and then a vertical stress was applied in stages $(9.8,19.6,39.2,78.5,157,314,628,1256 \mathrm{kPa})$ by a pneumatic cylinder by way of a loading rod. The time for each loading was set to $30 \mathrm{~min}$, as compression of the specimen immediately occurred and the volumetric behaviour did not appear time dependent during the compression stage. After reaching a prescribed vertical stress, a wetting and drying cycle was carried out while keeping the vertical stress constant. The wetting process started by permeating carbon dioxide slowly through the specimen without changing the void pressure for $30 \mathrm{~min}$ to remove any air, after which distilled water was permeated through the specimen by a slight difference in water level between the water tank and specimen container $\mathrm{h} 1$ until the specimen was fully submerged. After leaving the specimen submerged for $6 \mathrm{~h}$, the drying process was commenced by draining the void water from the specimen for $30 \mathrm{~min}$ through has light difference $\mathrm{h} 2$ in 


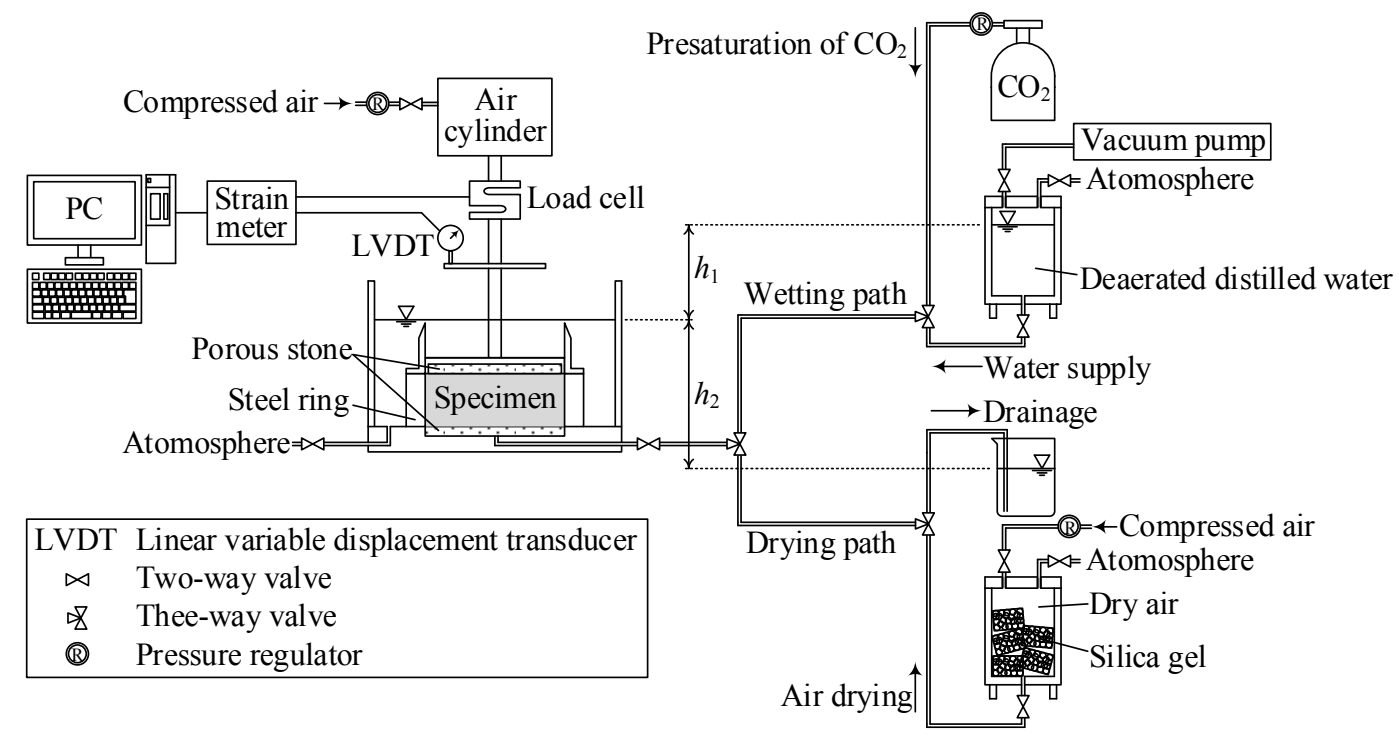

Fig. 3. Schematic set up experiment of one-dimensional compression slaking

water level. Silica gel packs were then set around the steel cylinder of the specimen container, and dried air was slowly permeated through the specimen for $48 \mathrm{~h}$ to ensure it was completely dried. This cycle of wetting and drying was repeated three times, during which time the volumetric behaviour was observed. Following the final drying process, the specimen was oven-dried and then sieved using only horizontal circular movements without any tapping impulse being added.

\section{Results and Discussions}

\subsection{Evolution of grading}

The slaking of weak rocks varies the grading, and the evolution in the grading affects mechanical characteristics of the soil resulting deformation. Thus, we characterized the change in the particle size distribution (PSD) observed after each test by a simple, scalar index. Among several indices, grading state index, $I_{G}[9,10]$, incorporates the idea of the limiting grading, and it could properly describe the evolution of the grading due to particle breakage and slaking [10, 11]. However, we herein selected the breakage parameter, $B_{r}[12]$, as it is defined relatively simply as the ratio of area of $\mathrm{ABCD}$ to $\mathrm{ABCF}$ as shown in Figure 4.

\subsection{Slaking-induced deformation on mudstones}

The particle size distribution (PSDs) of Kakegawa mudstone, Nou mudstone and Hattian Bala mudstone at the initial state, after compression, and after different numbers of wetting and drying cycles has drawn in Figure 5. The test results for the crushed Kakegawa and Nou mudstones under a vertical effective stress $\sigma_{v}{ }^{\prime}$ of 314 and $1256 \mathrm{kPa}$ are shown in Figures $5 \mathrm{a}$ and $5 \mathrm{~b}$, respectively, whereas the results for the crushed Hattian Bala mudstone under a vertical effective stress $\sigma_{v}{ }^{\prime}$ of $314 \mathrm{kPa}$ are provided in Figure 5c. It is evident from this that the particle size distributions of the crushed Kakegawa and
Nou mudstones were altered after compression, and that both mudstone types experience particle breakage during one-dimensional compression. It is also clear that there is a slightly greater change in grading at $1256 \mathrm{kPa}$, and so the evolution of grading due to particle breakage is related to an increase in the stress level. The crushed Hattian Bala mudstone, however, retains its original particle size distribution, and does not seem to exhibit any particle breakage under a stress of less than $314 \mathrm{kPa}$.

All of the crushed mudstone specimens experienced a variation in particle size distribution after wetting and drying, but the extent of this variation differed between mudstone types. The crushed Kakegawa and Nou mudstone exhibited a significant change in particle size distribution, and from the magnified photographs of the particles, it is evident that this is because many particles crumbled into finer particles.

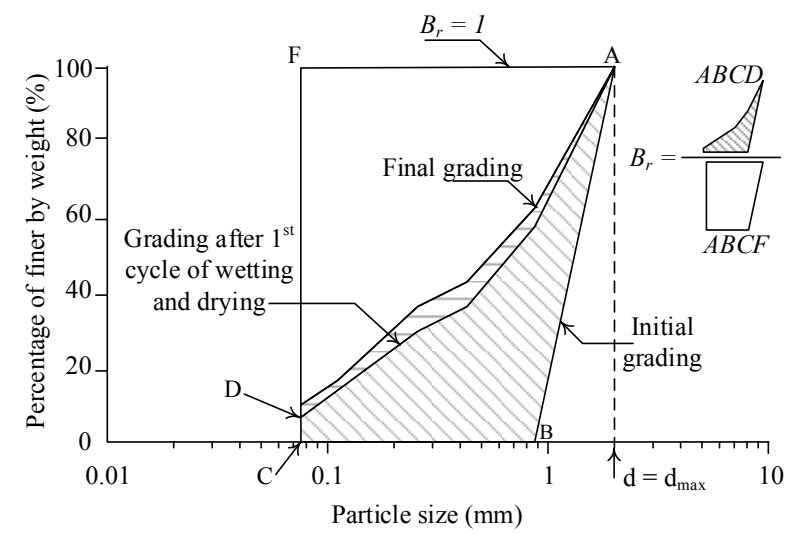

Fig. 4. Particle size distribution of geo-material to determine of breakage parameter $\left(B_{r}\right)$

In contrast, the change in grading of the crushed Hattian Bala mudstone in response to wetting and drying was relatively small, and the particles looked much the same before and after testing. Furthermore, the Hattian Bala mudstone particles did not contain any intragranular pores (Figure $2 b$ ), which would explain why there is so little change in particle size distribution during wetting 
and drying cycles. Throughout the tests, finer particles were gradually generated, but the maximum particle size remained constant. Kikumoto et al. [10] stated that breakage of particles increases the proportion of fine particles to fill the void space between larger particles without considerably changing the maximum particle size. The variation of PSD during wetting and drying cycles is also subject to such mechanism, and we can conclude that their grading state index, $I_{G}[10,11]$ can be utilized for describing the slaking phenomena.
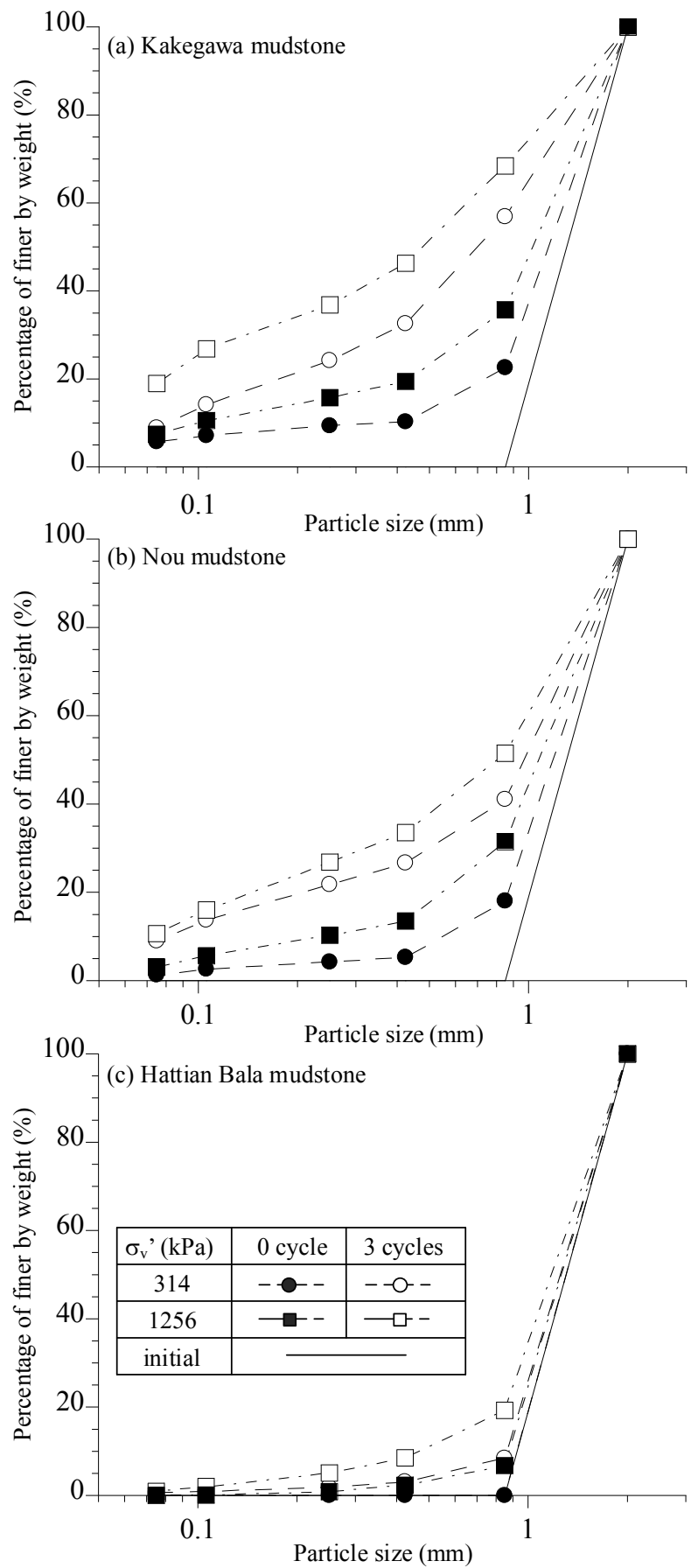

Fig. 5. The particle size distribution changes after compression ( 0 cycle) and after three cycles of wetting and drying
Figures 6, 7 and 8 show the relationships between the vertical effective stress $\left(\sigma_{v}{ }^{\prime}\right)$, number of wetting and drying cycles $(n)$, void ratio $(e)$ and breakage parameter $\left(B_{r}\right)$ for the crushed Kakegawa, Nou and Hattian Bala mudstone, respectively. The upper figures ( $a$ and $b$ ) illustrate the behavior in compression, whereas the lower figures (c and d) show the variation in grading. From the behavior of the crushed Kakegawa mudstone shown in Fig. 6 , it is clear that the value of $B_{r}$ (Figure 6c) increases to 0.12 at $314 \mathrm{kPa}$ and to 0.19 at $1256 \mathrm{kPa}$, which is consistent with particle crushing. The compression line in the semi-logarithmic plot of $e$ and $\log \sigma_{v}{ }^{\prime}$ also becomes steeper, which further confirms that particle crushing occurred [10]. After the final wetting and drying, the $B_{r}$ value increased to 0.44 (Figure 6d) and the specimen experienced significant compression, to the extent that the decrease in void ratio was larger than 0.6.

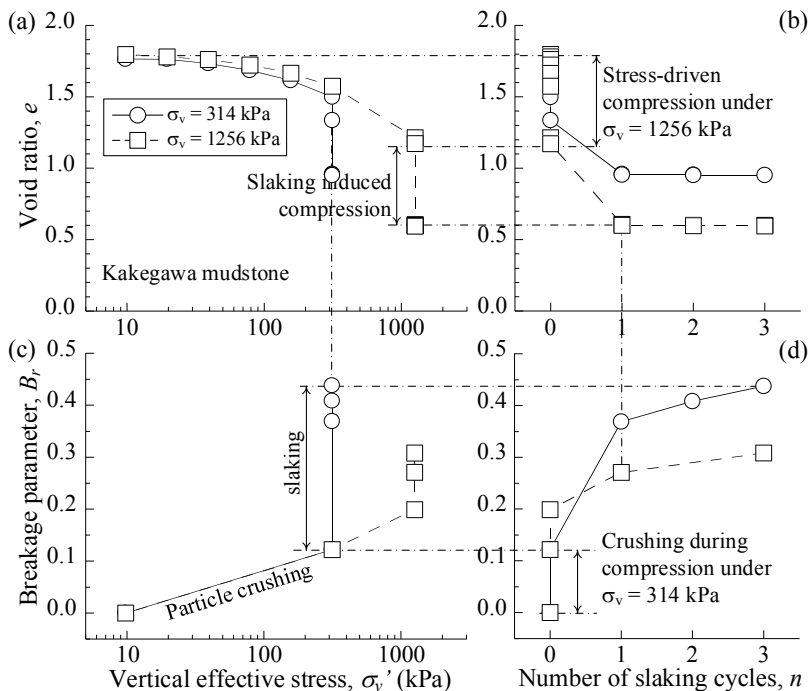

Fig. 6. Results of one-dimensional compression slaking tests on Kakegawa mudstone

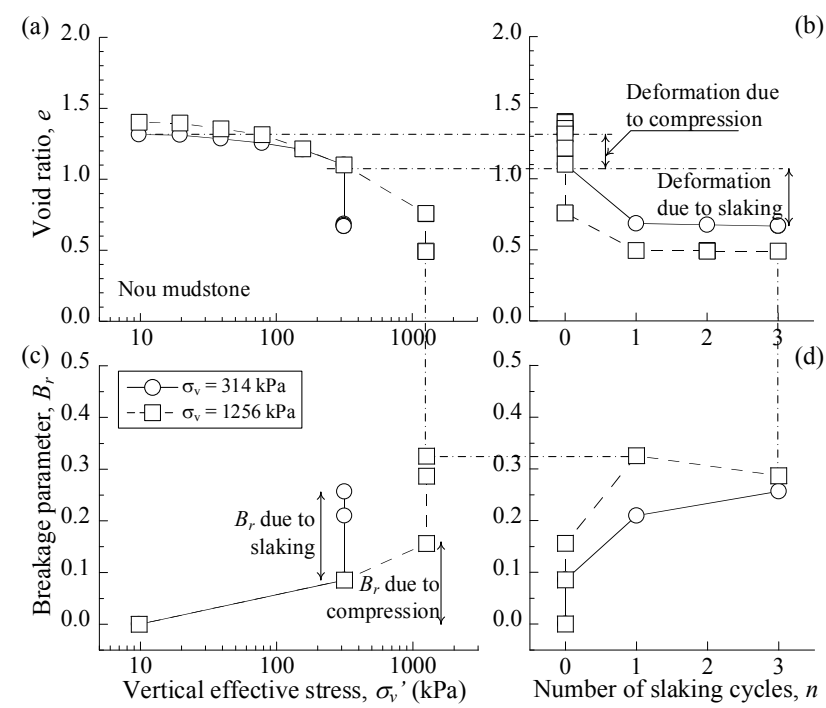

Fig. 7. Results of one-dimensional compression slaking tests on Nou mudstone 

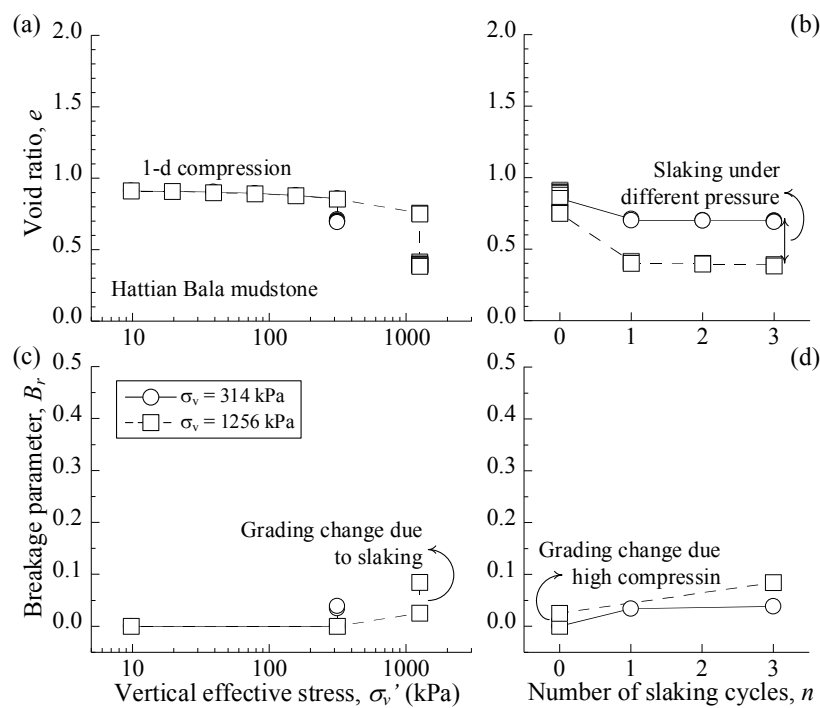

Fig. 8. Results of one-dimensional compression slaking tests on Hattian Bala mudstone

For the crushed Nou mudstone, the results for which is summarized in Figure 7, the $B_{r}$ value increases from 0.21 to 0.25 at $314 \mathrm{kPa}$ but decreases from 0.35 to 0.29 at $1256 \mathrm{kPa}$ during wetting and drying. It was confirmed the previous statement that breakage of particles increases the proportion of fine particles to fill the void space between larger particles without considerably changing the maximum particle size. The decrease in void ratio $e$ (volumetric compression) were not significant, comparing to the Kakegawa mudstone. In contrast, the increase in $B_{r}$ of the crushed Hattian Bala mudstone (Figure 8) was almost zero during the compression stage at $314 \mathrm{kPa}$ and slighlty increase due to high compression at $1256 \mathrm{kPa}$. The compression line in the $e-\ln \sigma_{v}{ }^{\prime}$ plane was comparatively flat. This indicates that the variation in $B_{r}$ during wetting and drying is rather small, and thus so is the volumetric compression induced by slaking. It can be inferred that slaking induced by wetting and drying cycle under a constant vertical effective stress causes substantial compression of geomaterials derived from mudstone.

\subsection{Countermeasure for reducing the slaking- induced deformation}

A rational countermeasure technique is needed for reducing the deformation due to slaking on the earth construction project. A serial number of one-dimensional compression slaking test has been prepared to get a better understanding related to these circumstances. The effect of loading/unloading compression history before wetting and drying cycle applied is one technique to consider. The Nou mudstone (Figure 2c) has selected and prepared for this purposes. The procedure of loading stage was similar with the previous one-dimensional compression slaking test that has explained. Except for the effect of loading/unloading, after the high compression has reached for $30 \mathrm{~min}$, then following with the unloading process to $314 \mathrm{kPa}$ for $30 \mathrm{~min}$. Next, the wetting and drying cycle was applied for one cycle. All of the test patterns in this section are summarized in Table 2 .
Table 2. The pattern of one-dimensional compression slaking test of Nou mudstone

\begin{tabular}{|c|c|c|c|c|c|c|c|c|}
\hline Case & 1 & 2 & 3 & 4 & 5 & 6 & 7 & 8 \\
\hline$e_{i}$ & 1.32 & 1.53 & 1.32 & 1.33 & 1.42 & 1.40 & 1.43 & 1.55 \\
\hline$\sigma_{v}^{\prime}$ & \multicolumn{4}{|c|}{314} & \multicolumn{2}{|c|}{1256} & \multicolumn{2}{|c|}{1256 to 314} \\
\hline$n$ & 0 & 1 & 1 & 3 & 1 & 3 & 1 & 1 \\
\hline
\end{tabular}

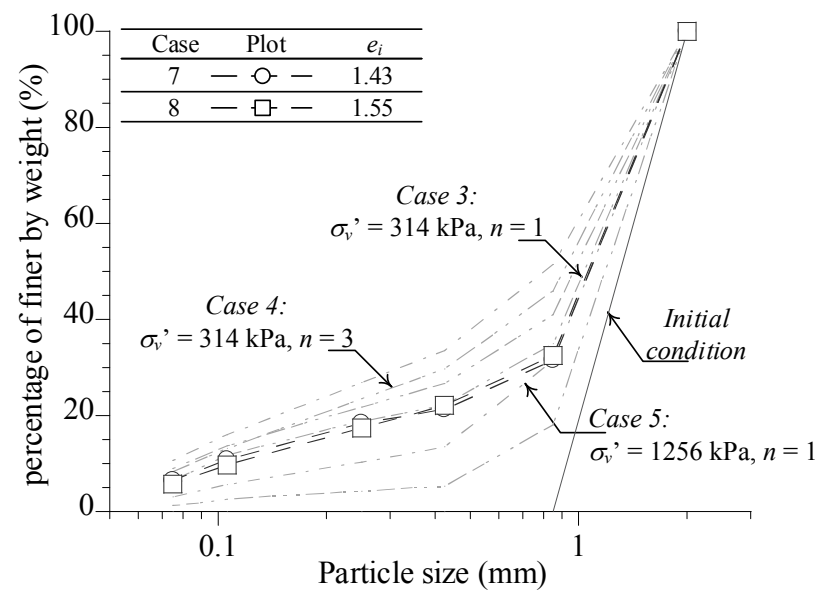

Fig. 9. Changes in particle size distribution after performed a stress history condition

The particle size distribution (PSDs) changes of each case patterns of the test are exhibited in Figure 9. It is significant that the PSD curve of case 7 and case 8 almost similar, despite the initial void ratio is different. It is inferred that the void ratio did not affect significantly to the grading changes. In spite of the high compression has been applied on the specimen, the final grading change (case 7 and case 8) almost similar with the test result of one-dimensional compression slaking under constant vertical effective stress at $314 \mathrm{kPa}$ (case 3). The total volume compression between case 3 and case 7 (Figure 10a) also exhibit the similar behavior, even though in case 7 the high compression stress has been applied in the beginning. It is pointed out that during the earth construction utilizing the geomaterial which has slaking properties, paying attention of roller compaction throughout the embanking work encourages the crushing of particles, controlling the occurrence of slaking under cyclic wetting and drying so that volumetric compression does not occur easily.

\section{Conclusions}

A number of one-dimensional compression slaking tests have been presented in this paper. The purpose was to investigate the mechanical consequences on the crushed weak rocks which are affected by wetting and drying cycles. In addition, a Scanning Electron Microscopy (SEM) has been performed to observe the surface morphology by magnifying the natural dimension of weak rock particles. The surface morphology of mudstone indicated the different slaking and deformation behavior, since the intra-granular pores within particle has been detected. The evolution of grading due to slaking will be easier to occur by the existences of intra-granular pores. 


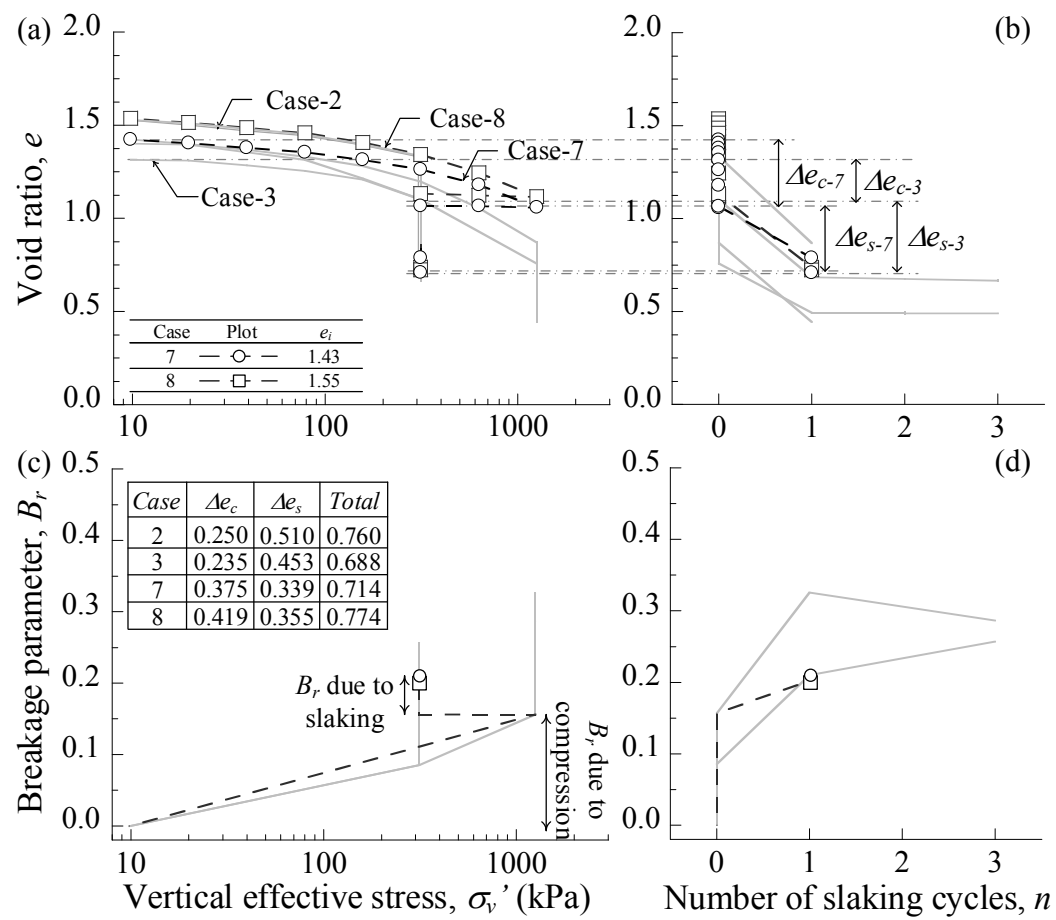

Fig. 10. Change in compressive properties during the loading and unloading stress of Nou mudstone

As a result, it causes an irreversible change in the mechanical properties of weak rocks attributable to variation in the density compaction. Moreover, the changes in particle size distribution as an evolution grading during compression can increase the compressibility of weak rocks, with wetting and drying cycles causing significant compression, despite the effective stress remains constant. Since the evolution of particle size distribution under constant confined stress occurs without a change in the maximum particle size, it can be described by existing indexes of grading such as breakage parameter $B_{r}$. Therefore, it seems reasonable to describe the effect of slaking on the deformation characteristic by representing the evolution of grading as the grading index $I_{G}$ and its evolution law in particle crushing theory. A countermeasure technique of the deformation behavior of weak rocks has been presented in this study. Changing the particle size distribution in the beginning by applying loading/unloading history before wetting and drying cycle has been exhibited the significant result. The compressibility during wetting and drying cycle decreases to $50 \%$ of conventional compression by applying this countermeasure method. In the earth construction works, the process of roller compaction is necessary to notice in order to encourage the crushing of particle. It aims to control the occurrence of slaking under wetting and drying cycle so that volumetric compression does not occur easily.

The authors would like to extend their appreciation and thanks to the earthworks research section of the NEXCO Research Institute for providing mudstones specimens. The first author is grateful to the University of Lampung for allowing him to pursue his PhD study and to continue the present research project at Yokohama National University. This research, financially supported by JSPS KAKENHI Grant Numbers 24360192, 16H06099 provided to the third author.

\section{References}

1. J. M. Mitchell, Fundamentals of Soil Behavior, John Wiley \& Sons (1993)

2. J.A. Franklin, R. Chandra, (1972), Int J Rocks Mech Mineral Sci 9, 3, 325-328, (1972)

3. L. E. Vallejo, R. A. Welsh, C. W. Lovell, M. K. Robinson, Rock for erosion control, ASTM Special Tech. Pub. (STP) 1177, 15-28 (1993)

4. N. Yoshida, K. Enami, K. Hosokawa, J. Testing and Evaluation 30, 3, 239-244 (2002)

5. L. E. Vallejo, D. Pappas, J Transportation Res B 2170, 84-89 (2010)

6. V. R. Schaefer, M. A. Birchmeir, Proc 18th Int Conf Soil Mech Geotech. Engrg, 1183-1186, (2013)

7. I. Rocchi, M. R. Coop, Géotechnique, 65, 6, 482-493 (2015)

8. T. Gautam, A. Shakoor, Eng Geol 166, 17-25 (2013)

9. M. Kikumoto, A. D. Putra, T. Fukuda, Géotechnique 66, 9, 771-785 (2016)

10. D. Muir Wood, Can Geotech J., 44, 11, 1329-1350 (72007)

11. M. Kikumoto, D. Muir Wood, A. Russell, Soils Found 50, 4, 547-563 (2010)

12. A. Sattar, K. Konagai, T. Kiyota, T. Ikeda, J. Johansson, Landslides, 8, 2, 171-182 (2011)

13. ASTM D6913-04, Annual Book of ASTM Standards, ASTM Int, (2004)

14. B. O. Hardin, J Geotech Eng, Proc ASCE 111, 10, 1177-1192, (1985) 